\title{
Validity and Reliability of the Life Transition Scale in Parents of Disabled Children Across the Life Transition Process
}

\author{
Sun Woo Hong ${ }^{1}$, JinShil Kim², Hwal Lan Bang ${ }^{3}$ \\ ${ }^{1}$ Associate Professor, Department of Emergency Medical Services, Daejeon University, Daejeon; ${ }^{2}$ Professor, College of Nursing, Gachon University, Incheon; \\ ${ }^{3}$ Assistant Professor, Department of Nursing, Andong National University, Andong, Korea
}

Purpose: The Life Transition Scale (LTS) consists of 24 items that assess the life transition process of parents of autistic children. This study aimed to examine the validity and reliability of the LTS in parents of children with a wide spectrum of disabilities. Methods: Data were collected from 260 parents of children with disabilities through self-report questionnaires. Validity was examined using exploratory and confirmative factor analysis to determine the factor structures of the LTS; socio-demographic differences in LTS scores were examined using the t-test or ANOVA. Reliability was examined using Cronbach's $\alpha$ coefficient. Results: A four-factor structure was validated $\left(x^{2}=640.0, p<.001, \mathrm{GFI}=.81\right.$, RMSEA=.07, NNFI=.89, CFI=.89, PNFI=.74, Q [ $\left.x^{2} / \mathrm{df}\right]$ $=2.60$ ). The validity of the LTS was verified by exploratory factor analysis, with factor loading ranging from .30 to .80 . There were significant differences in the accepting phase according to children's and parents' age and the type of disability, and in the wandering phase according to parental gender, educational level, job, and socioeconomic status. The Cronbach's $\alpha$ s for the reliability of each of the four structures were acceptable, within a range of .80 .90. Conclusion: The LTS is a valid and reliable measurement to assess the life transition process of parents with disabled children.

Key words: Disabled children; Parents; Life; Validation study

\section{Corresponding author Hwal Lan Bang \\ https://orcid.org/0000-0003-1115-6484}

Department of Nursing, Andong National University,

1375 Gyeongdong-ro, Andong 36729, Korea

TEL +82-54-820-5686 FAX +82-54-820-6730

E-MAIL luvlucie@anu.ac.kr

Received Jan 20, 2020 Revised Mar 11, 2020 Accepted Mar 16, 2020 (a) This is an Open Access article distributed under the terms of the Creative Commons Attribution NonCommercial License (http://creativecommons.org/licenses/by-nc/4.0/) which permits unrestricted noncommercial use, distribution, and reproduction in any medium, provided the original work is properly cited.

\section{INTRODUCTION}

\section{Need for Study}

Raising a child with a disability has a tremendous influence on the lives of all family members. Among the 2.49 million people with disabilities in Korea, 89,646 (3.6\%) are children under 19 years of age [1]. Intellectual disability affects approximately half (49.5\%) of disabled individuals, followed by autism spectrum disorder (17.5\%), brain lesions (13.7\%), and visual/auditory/speech disabilities (12.7\%) [1].

Common response behaviors of parents whose child is born with a disability or who recognize their child's disability include being shocked and emotionally disturbed [2]. In some cultures and societies, the pain of the parents of disabled children is often exacerbated by negative societal perceptions and religious convictions that disability is a type of punishment $[3,4]$. Although taking care of a child is a natural responsibility of a parent, raising a long-term dependent child with a disability involves heavy burdens, such as confronting the child's health problems (related or unrelated to the disability) in the long-term parenting process [5]. Parents may not feel the joy of life while raising disabled children who are susceptible to various health problems, such as pain and sleep disorders [6]. 
Parental distress may vary depending on the type of disability or the behavioral problems of the child [7-12]. Mothers commonly experience negative feelings toward children with intellectual disabilities who lack social skills compared to normal children. Furthermore, mothers are at risk of stress and depression due to their child's behavioral problems $[7,8]$. Children with cerebral palsy, who are classified as having brain lesions, struggle with limitations in their activities of daily living, sensory problems, difficulties of communication, and low intelligence. It was reported that mothers of children with cerebral palsy were commonly blamed for their children's disability. The mothers felt ashamed and stigmatized or experienced overt discrimination and rejection. Thus, they purposely avoided social gatherings, preferring to remain at home [9]. It was also reported that children with learning disabilities were emotionally unstable and subject to low self-esteem $[10,11]$. A recent study also demonstrated that depression in parents and emotional instability in disabled children may affect each other in a bidirectional relationship [12]; thus, disabled children may be at an elevated risk of abuse or neglect $[13,14]$.

Parental reactions or coping patterns may vary depending on the growth of disabled children across the developmental process [15]. The process of accepting and adapting to children's disabilities also varies [16,17]. Lee et al. [18,19] divided the life of parents of children with autism into five phases of transition: denying, wandering, devoting, mind controlling, and finally accepting. Lee, Hong, and Ju [20] modified the process of transition into four phases through confirmatory factor analysis: denying, wandering, despairing, and accepting, and developed a tool for measuring the process of life transition, the Life Transition Scale (LTS). The characteristics of the denying phase are ignorance and disbelief. In this phase, parents desire to hide their child's disability because they are self-conscious and intimidated. The wandering phase is the most stressful, marked by feelings of unfairness, fear, anxiety, sadness, shock, disappointment, depression, and guilt. The despairing phase involves being worn out and feeling helpless because there are no improvements in the symptoms of their child's disability. Eventually, in the accepting phase, parents reorganize their lives to care for their children with a disability, and this period is marked by feelings of acceptance, gratitude, and mutual dependence. Once they reach the accepting phase, parents can easily move beyond the emotions they initially felt, even if a new crisis emerges and reverts them to the wandering or the despairing phase, and accept that they have done their best even if the disability does not improve despite all their efforts. Therefore, the accepting phase acts as a mediating factor between the behavior of the child and the mental health of the parent, and it is an im- portant factor for parents in coping with the behaviors of children with disabilities [21].

Parents of autistic children who face substantial burdens of care often follow an adjustment process throughout the lifecourse of their children's illness trajectory. Likewise, the parents of children with other types of disabilities, such as cerebral palsy, also undergo substantially distressful circumstances caused by their children's disability. Thus, hypothetically, parents of children with other types of disabilities are likely to follow the same adjustment process throughout the child's illness trajectory as do the parents of autistic children. Although specific aspects of the process of parents accepting a child's disability vary by the type of disability [16,17], it is necessary to acquire information about how parents cope with the impact of their child's disability and how they perceive their circumstances. The phase of transition needs to be identified to help children with disabilities and their families live a healthy life, by facilitating the parents' progress from the denying, wandering, and despair phases to the accepting phase. It is also necessary to measure the transition process of individual parents raising a child with a disability and to identify differences and factors that influence each phase of the transition process depending on the characteristics of the child and the parent.

Accordingly, the feasibility of the LTS developed by Lee et al. [20] was tested among parents of children with various disabilities, other than autistic spectrum disorder, by examining whether the transition processes fit the adjustment of parents of children with other disabilities. Specifically, this study was aimed to examine the validity and reliability of the LTS in parents of children with a wide spectrum of disabilities and to identify differences in the life transition process according to parents' socio-demographic characteristics. It is expected that this process will provide a basis for determining specialized nursing interventions at each phase for the parents of children with disabilities.

\section{METHODS}

\section{Study Design}

This was a validation study to examine whether the LTS developed by Lee et al. [20] could be applied to parents of children with different types of disabilities and to test the validity and reliability of the scale.

\section{Data Collection and Procedures}

This study was approved by the Institutional Review Board of Wonkwang Health Science University (WKIRB-201603-SB- 
011). Data were collected from May 20 to August 31, 2016 through self-report questionnaires. Participants were recruited from daycare centers for children with disabilities, lifelong education centers, and local children's centers for the disabled. Before data collection, a questionnaire with a letter explaining the purpose of this study was sent to the head of the institutions. After obtaining approval from the institution, questionnaire booklets with a stamped envelope for their return were distributed to the parents of children with disabilities. Each envelope contained a letter guaranteeing the anonymity and confidentiality of the data, an informed consent form, instructions, and a token of appreciation. The sample size of 183 was estimated with $\alpha=.05$, a medium effect size of .30 , and a power of .90 using $G^{*}$ Power version 3.1.7. To account for the potential for a high drop-out rate [20], 320 questionnaires were mailed out, and of the 282 returned questionnaires (response rate $=88.1 \%$ ), 22 were incomplete. Thus, 260 responses were used for the data analysis.

\section{Measurements}

\section{1) The Life Transition Scale for parents of children with autism}

The LTS is a parent-reported scale that assesses the process of life transition of parents of children with autism spectrum disorder [20]. The researchers did not modify any existing questions when applying the LTS to parents of children with other types of disabilities, because the LTS consists of questions about 'feelings' experienced by parents of children with disabilities and does not refer to specific disabilities. Parents were instructed to mark their current feelings regarding their lives on a 4-point Likert-type scale (not true $=1$ to completely or always true $=4$ ). This scale consisted of 24 items and had four subscales, including phases of denying (6 items), wandering (8 items), despairing (4 items), and accepting (6 items). For each phase, scores ranging from 1 to 4 were summed and averaged, to compare the life transitional feelings across the phases. Validity and reliability were documented previously through confirmatory factor analysis. The internal consistency of each of the four subscales was determined to be acceptable. In a previous study with parents of autistic children, Cronbach's $\alpha$ coefficient of the total scale was .83, and the coefficients for the subscales were .86 for denying, 90 for wandering, .77 for despairing, and .85 for accepting [20].

\section{Data Analysis}

Descriptive statistics were calculated to represent the general characteristics of the sample. Confirmatory factor analysis using a structural equation model was performed to test the theoretical fit of the subscales of the LTS. In this study, the maximum likelihood method was used to estimate the parameters. The goodness-of-fit test to evaluate whether a measurement model is suitable for a certain dataset uses several fit indices. In this study, the $x^{2}$ test $\left(x^{2}\right)$, degrees of freedom (df), goodness-of-fit index (GFI), root mean square error of approximation (RMSEA), non-normed fit index (NNFI), comparative fit index (CFI), parsimonious normed fit index (PNFI), and Q (normed $x^{2} ; x^{2} / \mathrm{df}$ ) were used. The internal consistency of the LTS and its subscales was assessed by Cronbach's $\alpha$. Differences in the life transition process according to the socio-demographic characteristics of the children and parents were analyzed using the t-test and one-way analysis of variance with the Scheffé post hoc test for group comparisons. The collected data were analyzed using SPSS for Windows version 22.0 and AMOS version 22.0 (IBM Corp., Armonk, NY, USA) with the level of significance set at a $p$-value of .050 .

\section{RESULTS}

\section{Participants' Socio-demographic Characteristics}

The participants were 114 fathers (43.8\%) and 146 mothers $(56.2 \%)$. The mean age of the participants was 41.9 years $(\mathrm{SD}=7.1)$. By age category, $106(40.8 \%)$ were 39 years old or younger, $120(46.1 \%)$ were $40 \sim 49$ years old, and $34(13.1 \%)$ were 50 years or older. The distribution of educational levels was fairly even, as 132 (50.8\%) participants had a high school education or lower, and 128 (49.2\%) had a college education or higher. More than half reported religious affiliations (56.2\%) and had a job (53.1\%). The household income levels among the participants were as follows: 101 (38.8\%) earned 3 million Korean won per month or more, 86 (33.1\%) earned between 2 and 2.99 million Korean won per month, and 73 (28.1\%) earned less than 2 million Korean won per month (Table 1).

The mean age of the children with a disability was 11.0 years $(\mathrm{SD}=6.5)$. The children consisted of 80 preschoolers $(\leq 6$ years old) (30.8\%), 102 elementary school students (7 12 years old) (39.2\%), 39 adolescents (13 18 years old) (15.0\%), and 39 adults ( $\geq 19$ years old) $(15.0 \%)$. There were 159 male $(61.2 \%)$ and 101 female $(38.8 \%)$ children. With respect to birth order, 128 (49.2\%) children were first-born, followed by 106 (40.8\%) who were second-born, and $26(10.0 \%)$ who were third- or later-born. Approximately half $(48.8 \%)$ of the children had intellectual disabilities, followed by 86 (33.1\%) with brain damage, and 47 (18.1\%) with visual/auditory or other disabilities. The disability levels of the children were as follows: 159 $(61.1 \%)$ in the first degree, $47(18.1 \%)$ in the second degree, and $54(20.8 \%)$ in the third degree or over (Table 1$)$. 
Table 1. Socio-demographic Characteristics of Children and Parents

$(N=260)$

\begin{tabular}{|c|c|c|c|c|}
\hline Variables & Characteristics & Categories & $\mathrm{n}(\%)$ & $\mathrm{M} \pm \mathrm{SD}$ \\
\hline \multirow[t]{15}{*}{ Children } & \multirow[t]{4}{*}{ Age (year) } & $\leq 6$ (preschoolers) & $80(30.8)$ & \multirow[t]{15}{*}{$11.0 \pm 6.5$} \\
\hline & & 7 12 (elementary school children) & $102(39.2)$ & \\
\hline & & $13 \sim 18$ (adolescents) & $39(15.0)$ & \\
\hline & & $\geq 19$ (adults) & $39(15.0)$ & \\
\hline & \multirow[t]{2}{*}{ Gender } & Male & $159(61.2)$ & \\
\hline & & Female & $101(38.8)$ & \\
\hline & \multirow[t]{3}{*}{ Birth order } & First & $128(49.2)$ & \\
\hline & & Second & $106(40.8)$ & \\
\hline & & Third & $26(10.0)$ & \\
\hline & \multirow{3}{*}{ Type of disability } & Intellectual disability & $127(48.8)$ & \\
\hline & & Brain damage & $86(33.1)$ & \\
\hline & & Visual/auditory disorder & $47(18.1)$ & \\
\hline & \multirow{3}{*}{ Level of disability } & First degree & $159(61.1)$ & \\
\hline & & Second degree & $47(18.1)$ & \\
\hline & & $\geq$ Third degree & $54(20.8)$ & \\
\hline \multirow[t]{14}{*}{ Parents } & \multirow[t]{3}{*}{ Age (year) } & $\leq 39$ & $106(40.8)$ & \multirow[t]{14}{*}{$41.9 \pm 7.1$} \\
\hline & & $40 \sim 49$ & $120(46.1)$ & \\
\hline & & $\geq 50$ & $34(13.1)$ & \\
\hline & \multirow[t]{2}{*}{ Gender } & Male & $114(43.8)$ & \\
\hline & & Female & $146(56.2)$ & \\
\hline & \multirow[t]{2}{*}{ Education } & $\leq$ High school & $132(50.8)$ & \\
\hline & & $\geq$ College & $128(49.2)$ & \\
\hline & \multirow[t]{2}{*}{ Religion } & None & $114(43.8)$ & \\
\hline & & Yes & $146(56.2)$ & \\
\hline & \multirow[t]{2}{*}{ Job } & None & $122(46.9)$ & \\
\hline & & Yes & $138(53.1)$ & \\
\hline & \multirow{3}{*}{$\begin{array}{l}\text { Monthly household income } \\
(10,000 \mathrm{KRW})\end{array}$} & $<200$ & $73(28.1)$ & \\
\hline & & 200 299 & $86(33.1)$ & \\
\hline & & $\geq 300$ & $101(38.8)$ & \\
\hline
\end{tabular}

KRW=Korean Won.

\section{Validity and Reliability Analysis}

Exploratory factor analysis was performed to test whether the 24 items of the LTS developed for parents of autistic children by Lee et al. [20] could be applied to parents of children with different types of disabilities, and confirmatory factor analysis was performed to test the theoretical fit of the subscales of the LTS. Cronbach's $\alpha$ was analyzed to assess the internal consistency of LTS and its subscales.

\section{1) Exploratory factor analysis}

The sample size was confirmed to be appropriate for the factor analysis because the values of the Keiser-Meyer-Olkin test and Bartlett's test for sphericity of the 24 questions were .94 and $x^{2}=3,720.57(p<.001)$, respectively. Four factors were extracted by principal component analysis based on eigenvalues greater than 1.0 and by a scree plot and were classified as wandering (8 items), accepting (6 items), denying (6 items), and despairing (4 items). The number of items comprising each factor was 4 to 8 , and the factor loading of each item was distributed between .30 and .80 . Although the factor loading of the 'I want to give up my child' item was .57 in the denying phase and .30 in the wandering phase, this item was included in the wandering phase because it was classified accordingly at the time of tool development. Factor 1, the denying phase, explained $43.96 \%$ of the variance; factor 2 , the wandering phase, explained $9.55 \%$; factor 3 , the accepting phase, explained $6.02 \%$; and factor 4 , the despairing phase, explained $4.52 \%$. The cumulative proportion of variance explained was $64.05 \%$ (Table 2).

\section{2) Confirmatory factor analysis}

As a result of evaluating the model's goodness of fit for the four structures (the 24-item instrument), the absolute fit index 
Table 2. Factor Analysis of Items

$(N=260)$

\begin{tabular}{|c|c|c|c|c|c|c|c|c|}
\hline \multirow{2}{*}{ No. } & \multirow{2}{*}{ Item } & \multicolumn{4}{|c|}{ Factor loading } & \multirow{2}{*}{$\begin{array}{c}\text { Eigen } \\
\text { values }\end{array}$} & \multirow{2}{*}{$\begin{array}{c}\% \text { of } \\
\text { variance }\end{array}$} & \multirow{2}{*}{$\begin{array}{c}\text { Cumulative } \\
(\%)\end{array}$} \\
\hline & & Denying & Wandering & Accepting & Despairing & & & \\
\hline$x 1$ & I feel that everything is confusing & .52 & .27 & .46 & -01 & \multirow[t]{6}{*}{10.55} & \multirow[t]{6}{*}{43.96} & \multirow[t]{6}{*}{43.96} \\
\hline$x 5$ & I want to hide my child's disability & .80 & .01 & .30 & -.16 & & & \\
\hline$x 7$ & I sometimes shrink up in shame because of my child & .51 & .45 & .33 & -.19 & & & \\
\hline x10 & I don't like to meet people & .64 & .48 & .04 & -.19 & & & \\
\hline$x 17$ & I'm afraid of people's gaze & .71 & .35 & .22 & -.22 & & & \\
\hline$x 22$ & I'm ashamed to take my child around & .70 & .13 & .26 & -.29 & & & \\
\hline$x 6$ & I feel sorry for myself & .43 & .53 & .42 & -.10 & \multirow[t]{8}{*}{2.29} & \multirow[t]{8}{*}{9.55} & \multirow[t]{8}{*}{53.52} \\
\hline$x 8$ & I want to give up my child & .57 & .30 & .01 & -.38 & & & \\
\hline x16 & I don't have my own life & .12 & .78 & .29 & -.03 & & & \\
\hline$x 18$ & My life itself is meaningless & .51 & .65 & .07 & -.29 & & & \\
\hline x19 & I don't care about anybody but my child & .14 & .79 & .16 & -.03 & & & \\
\hline$x 20$ & I'm exhausted with no hope & .53 & .54 & .25 & -.21 & & & \\
\hline$x 28$ & I'm tired of living because of my child & .38 & .46 & .42 & -.32 & & & \\
\hline$x 29$ & I have a lot of burden and stress & .24 & .57 & .43 & -.23 & & & \\
\hline$x 2$ & I feel thankful to my child & -.28 & -.08 & 69 & -.12 & \multirow[t]{6}{*}{1.44} & \multirow[t]{6}{*}{6.02} & \multirow[t]{6}{*}{59.54} \\
\hline$x 9$ & I've gained rather than lost from my child & -.06 & -.11 & .74 & -.17 & & & \\
\hline x11 & I feel joy in my child & -.29 & -.11 & .64 & -.01 & & & \\
\hline$x 23$ & I think my child is a special gift from God & -.11 & -.03 & .75 & -.11 & & & \\
\hline$x 24$ & My child made me thankful for small things & -.19 & -.12 & .74 & -.03 & & & \\
\hline$x 27$ & My life was enriched because of my child & -.01 & -.08 & .64 & -.36 & & & \\
\hline$x 3$ & I feel fear and hopeless & .28 & .19 & -.10 & .71 & \multirow[t]{4}{*}{1.08} & \multirow[t]{4}{*}{4.52} & \multirow[t]{4}{*}{64.05} \\
\hline$x 12$ & It breaks my heart to think of my child & .09 & .14 & -.10 & .76 & & & \\
\hline x14 & I'm unhappy comparing my child with others & .18 & .19 & -.19 & .65 & & & \\
\hline$x 26$ & I'm at a loss about the future & .18 & .40 & -.31 & .60 & & & \\
\hline & Reliability & .88 & .90 & .84 & .80 & \multicolumn{3}{|c|}{ Total reliability .84} \\
\hline
\end{tabular}

was $x^{2}=640.0(p<.001)$, GFI was .81 , RMSEA was .07 , NNFI was .89 , CFI was .89 , the PNFI was .74, and $Q\left(x^{2} / \mathrm{df}\right)$ was 2.60 . Thus, the measured model was found to be appropriate (Table 3, Figure 1).

\section{3) Reliability}

The internal consistency (alpha coefficient) of the total scale was .84 . The alpha coefficients were $.88, .90, .80$, and .84 for the denying, wandering, despairing, and accepting phases, respectively (Table 2).

\section{Differences in the Life Transition Process According to Socio-demographic Characteristics}

Statistically significant differences were found among the scores for the denying phase depending on household income, but no differences were found among the groups. That is, participants with the lowest category of household income (less than 2 million Korean won per month) had a higher score for the denying phase than those with an income of 3 million Korean won per month or higher $(\mathrm{F}=5.76, p=.004)$.

Statistically significant differences were found in the scores 
Table 3. Fitness Statistics of the Current and Original Models

$(N=260)$

\begin{tabular}{|c|c|c|c|c|c|c|c|c|}
\hline \multirow{2}{*}{ Fitness } & \multicolumn{4}{|c|}{ Absolute fit measure } & \multicolumn{2}{|c|}{ Incremental fit measure } & \multicolumn{2}{|c|}{ Parsimonious fit measure } \\
\hline & $x^{2}(p)$ & df & GFI & RMSEA & NNFI & CFI & PNFI & $\mathrm{Q}\left(\chi^{2} / \mathrm{df}\right)$ \\
\hline Criteria & $(\geq .050)$ & & $\geq .90$ & $.05 \sim .08$ & $\geq .90$ & $\geq .90$ & $\geq .60$ & $\leq 3.00$ \\
\hline Current measured model & $640.00(<.001)$ & 246 & .81 & .07 & .89 & .89 & .74 & 2.60 \\
\hline Original measured model & $541.23(<.001)$ & 246 & .82 & .07 & .89 & .89 & .73 & 2.20 \\
\hline
\end{tabular}

$\mathrm{dF}=$ Degrees of freedom; GFI=Goodness-of-fit index; RMSEA=Root mean squared error of approximation; NNFI=Non-normed fit index; CFI=Comparative fit index; PNFI=Parsimony normed fit index.

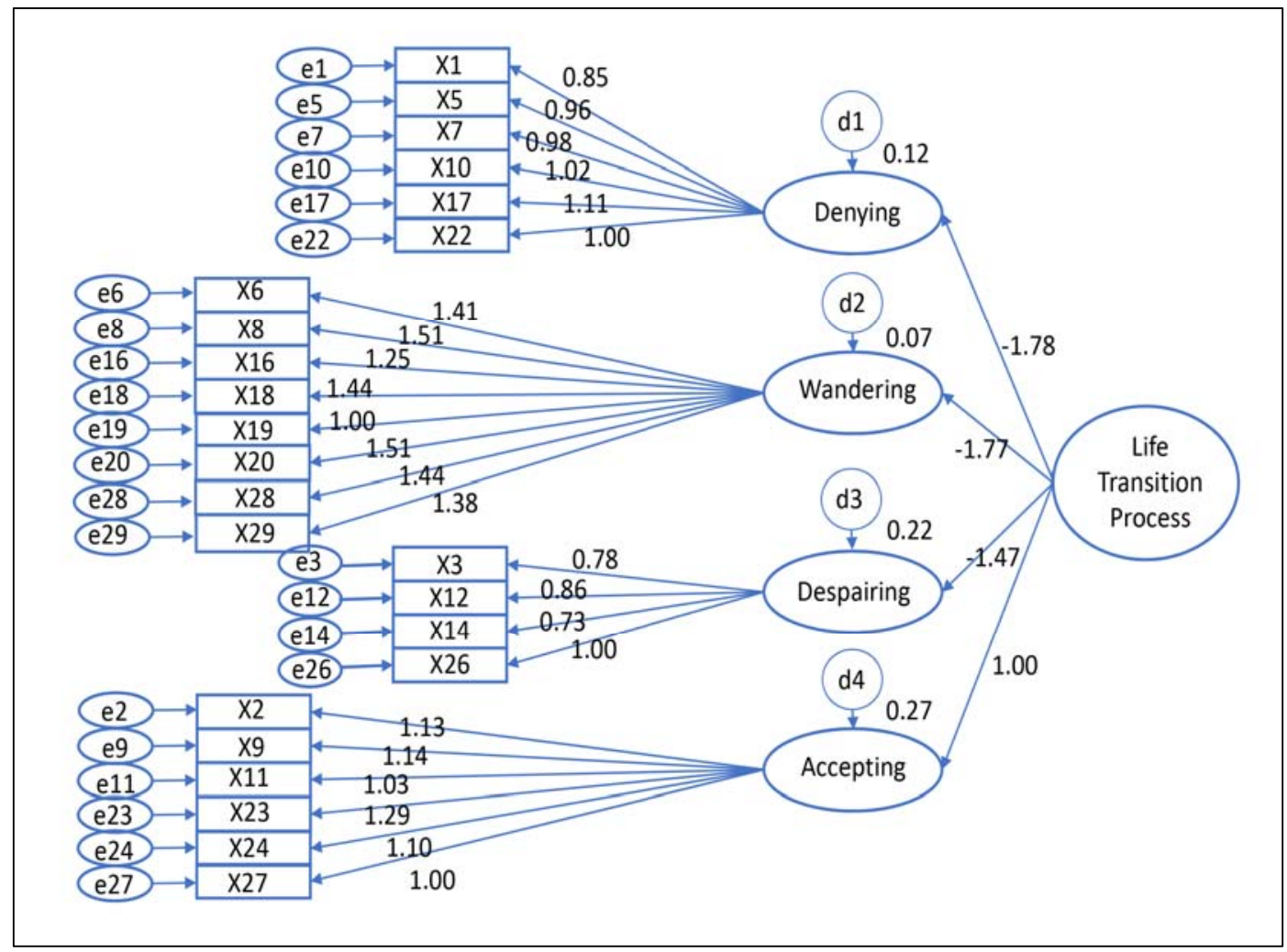

Figure 1. The path diagram of the current measured model.

of the wandering phase depending on the parent's gender $(\mathrm{t}=3.44, p=.001)$, educational level $(\mathrm{t}=2.89, p=.038)$, employment status $(\mathrm{t}=3.39, p=.001)$, and household income $(\mathrm{F}=12.42$, $p<.001)$. Mothers had higher scores than fathers $(\mathrm{t}=3.44, p=$ .001). Respondents without a job, with a lower educational level, and in the lowest category of household income (less than 2 million Korean won) had a higher score in the wandering phase than the other respondents.

A statistically significant difference was found in the scores of the despairing phase depending on household income $(\mathrm{F}=$ $3.46 p=.033$ ). Respondents with a household income in the lowest category (less than 2 million Korean won) showed higher scores of the despairing phase than those with a household income in the highest category ( 3 million Korean won per month or higher).

Statistically significant differences were found in the accepting phase depending on the child's age $(\mathrm{F}=9.06 p<.001)$ and type of disability $(\mathrm{F}=5.21 p=.006)$; the parent's age $(\mathrm{F}=$ 5.70, $p=.004)$, educational level $(\mathrm{t}=2.13, p=.033)$, and religion $(\mathrm{t}=3.60, p<.001)$; and household income $(\mathrm{F}=6.39, p=.002)$. Parents who had a child who was 12 years of age or younger or with brain damage scored higher in this phase than the other respondents. Respondents who were 39 years of age or younger and who had a religious affiliation, higher educational level, and a household income in the highest category scored higher for the accepting phase than the other respondents (Table 4). 
Table 4. Differences in the Life Transition Process According to the Socio-demographic Characteristics of Children and Parents ( $N=260)$

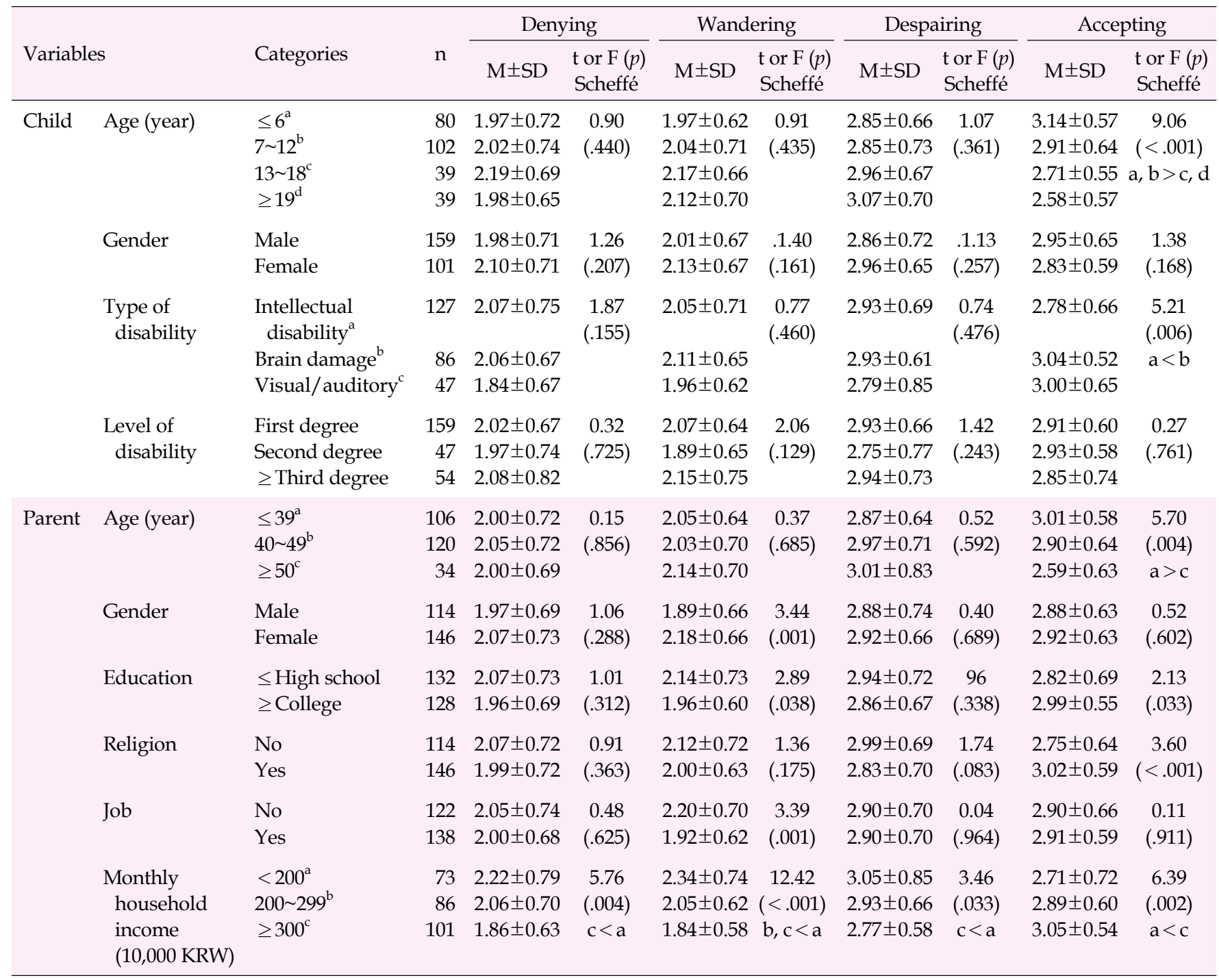

KRW=Korean Won.

\section{DISCUSSION}

In this study, the researchers investigated whether the LTS, which was developed for parents of children with autism, is valid and reliable for the parents of children with other types of disabilities. Furthermore, the differences and characteristics of each phase of the life transition process according to the demographic characteristics of the study participants were examined.

The results indicated that it is feasible to use the LTS to assess the life transition process of parents of children with other types of disabilities. The validity of the LTS was verified by exploratory factor analysis, with factor loading ranging from .30 to .80 [22]. The cumulative percentage of variance explained was $64.05 \%$, higher than the $62 \%$ reported in a factor analysis conducted among the parents of autistic children [20].

The results of the confirmatory factor analysis provided further support for good model fit, as the model fit indices were similar to those from parents of children with autism. Four factors emerged, which were labeled as the wandering phase (8 items), accepting phase (6 items), denying phase (6 items), and despairing phase (4 items).

The reliability of the internal consistency of the entire LTS was .84, which is higher than the internal consistency of .81 reported in a past study conducted on the parents of children with autism [23]. Each factor attained a high reliability: .88 for the denying phase, .90 for the wandering phase, .80 for the despairing phase, and .84 for the accepting phase. Thus, the theoretical fit and the reliability of the LTS developed for parents of autistic children were applicable to evaluating the tran- 
sition process of the lives of parents of children with various types of disabilities in addition to autism spectrum disorder.

No significant differences were found in the life transition process of parents of children with a disability according to their socio-demographic characteristics. The transition process experienced by the parents of children with other types of disabilities (intellectual disability, brain damage, and visual/ auditory disorders) showed no differences during the denying, wandering, and despairing phases in relation to the disability type, disability rating, or their age and gender. Although it was expected that the distress experienced by parents would be different because the behavioral patterns of children with disabilities vary widely, the results of this study suggest that parents are traumatized and experience pain only because of the fact that their children are disabled, regardless of the type or level of disability.

However, the score of the accepting phase for parents of children with brain damage was significantly higher than that of parents of children with intellectual disabilities. This disparity is assumed to be caused by differences in communication skills or behavior between children with brain damage and those with intellectual disabilities, but further study is needed because no prior studies have investigated these differences. Lee and Hong's study [23] challenged the assumption of a prior study that parents of adults with disabilities would accept and appreciate their adult children's disabilities positively because there were no differences in their scores for the accepting phase, which depended on the age of the child and that of the parent. Lee and Hong [23] explained that the patterns of pain experienced by parents in the course of an autistic child's growth into an adult are constantly changing, especially as parents themselves grow older and more subject to anxiety and despair about the future of their children with disabilities.

In this study, however, the score of the accepting phase of the parents of preschoolers and school-age children was significantly higher than that of parents with adolescent or adult children. Parents aged 39 years or younger reported a higher score for the accepting phase than parents aged 50 years or older, indicating that parents of adults with disabilities were not able to accept their children's disabilities. Parents of adults with disabilities are in fact likely to suffer more than parents of young children with disabilities. In a study by Shim and Nam [24], a mother who lived with her adult disabled child stated that she could not expect a normal life for her child as an adult, as her child would not be able to live independently, earn money, or get married. The mother also stated that as she grew older and became mentally and physically weaker, she had increasingly serious anxiety, concern, and fear about the possibility that she would no longer be able to take care of her child due to aging and death. Kim, Kim, and Kim [25] reported that parents of children faced a heavy physical and financial burden, but as their children grew to adulthood, the physical and financial burden decreased while the emotional and social burden continued to increase, reflecting the changing aspects of the parents' burden of caring for their disabled children. That is, from a life-cycle perspective, while parents who raise children with disabilities can reach the accepting phase after going through the earlier phases of shock, denying and wandering, the nature of parental distress evolves into a set of relatively intangible challenges as their children and the parents themselves grow older. As a result, addressing families with adult children with disabilities requires an approach different from that aimed at families raising young children with disabilities, and a social support system is necessary to provide continuing care even after the parents' deaths.

Meanwhile, the process of life transition of parents of children with disabilities showed differences depending on the parents' own demographic characteristics, indicating that their socioeconomic attributes were more closely related to the life transition process than their children's disability or behavior. Lee [5] reported that maternal caring behavior for a child with a disability was most strongly affected by parenting self-esteem, rather than by behavioral problems, socioeconomic status, perceived stigma, objective burdens, or the functional limitations caused by the child's disability. In other words, parents' awareness of their own values and abilities is a process of controlling or striving for certain situations. Thus, in order to promote maternal caring behavior and the health of disabled children, the primary focus should be on mothers' parenting self-esteem.

In this study, no significant differences were found according to the gender of the parents in the denying, despairing, and accepting scores, but the mothers' wandering phase scores were significantly higher than those of the fathers, and parents without a job scored significantly higher in the wandering phase than those with a job. It should be considered that it might be difficult for mothers of children with disabilities to get a job, as they are the main caregivers of their children. In the wandering phase, parents become susceptible to emotional instability and lose their sense of purpose in their own lives. Instead, every effort is directed at making the disabled child normal, and as such, the wandering phase is described as the most conflicting phase for the mother of a disabled child [18]. In a study of parents of autistic children, Lee and Hong [23] reported that mothers' wandering phase scores were significantly higher than those of fathers because the role of caring for disabled children was largely assigned to mothers. Nevertheless, it should not be overlooked that the parents' marriage is an important factor in raising disabled children. 
As shown by Lashewicz et al. [16], fathers also can experience serious emotional crises. It was reported that $6 \sim 8 \%$ of fathers of children with intellectual disabilities had severe depression, and they had higher stress than fathers of normal children [26,27]. Lee and Hong [23] also reported that the accepting phase scores of parents of autistic children were low. They argued that researchers should maintain interest in the existence, distress, and role of fathers in the family. Integration programs of the family unit involving fathers should be developed to enhance family solidarity and adaptability.

In this study, the wandering phase scores of parents with a lower level of education were higher, but the accepting phase scores were lower, and parents belonging to the lowest income category scored higher in the wandering, denying, and despairing phases and lower in the accepting phase than those in the highest income category. Considering that the parents' level of education and financial status are negatively correlated with emotional support and child rearing [28] and that the social support or financial resources of a family has a buffer effect between children's behavioral problems and parental stress [29], it is necessary to give attention and support to families with low socioeconomic status.

In particular, the degree of poverty in assets was found to be related to the life cycle of parents of children with intellectual disabilities, as $55 \%$ of young parents were in financial poverty, and $55 \%$ of parents aged $45 \sim 54$ years were reported to have the highest category of assets, but their financial status dropped sharply as they became senior citizens [30]. Because low accepting phase scores among the parents of disabled adolescents or adults and parents over the age of 50 are also associated with financial poverty, special attention and support are needed for these parents.

Differences in the transition process of parents of children with disabilities according to their demographic characteristics were identified. It is suggested that support be provided to parents of children with various types of disabilities to overcome the phases of denying, wandering, and despairing and to reach the accepting phase. It is also suggested that support programs and special nursing interventions be developed for older parents of adult children.

\section{CONCLUSION}

In this study, the psychometric properties of the LTS, which was originally developed for parents of children with autism, were examined and the feasibility of using the LTS for parents of children with other types of disabilities was established. Both exploratory and confirmatory factor analyses showed that the scale consisted of a four-factor structure with a good model fit. Reliability was also supported with a total of 24 items, and the subscales had acceptable internal consistency coefficients, as shown by Cronbach's $\alpha$ coefficients of .84 for the total scale and $.88, .90, .80$, and .84 for the denying, wandering, despairing, and accepting phases, respectively.

This study is significant in terms of nursing research and practice in that the LTS developed for parents of children with autism was tested for theoretical suitability and reliability. It can be used for measuring the process of life transition in parents of children with a wide spectrum of disabilities.

\section{Conflict of interest}

No existing or potential conflict of interest relevant to this article was reported.

\section{Acknowledgements}

The authors are grateful to Dr. AR Lee for her assistance in data collection and invaluable comments.

\section{REFERENCES}

1. Ministry of Health and Welfare. 2017 Status of the disabled [Internet]. Sejong: Ministry of Health and Welfare; 2018 [cited 2018 April 28]. Available from:

http://kosis.kr/common/meta_onedepth.jsp?vwcd=MT_OTITLE \&listid=101_11761

2. Boström PK, Broberg M, Hwang P. Parents' descriptions and experiences of young children recently diagnosed with intellectual disability. Child: Care, Health and Development. 2010;36(1):93-100. https://doi.org/10.1111/j.1365-2214.2009.01036.x

3. Dabrowska A, Pisula E. Parenting stress and coping styles in mothers and fathers of pre-school children with autism and Down syndrome. Journal of Intellectual Disability Research. 2010;54(3):266-280. https://doi.org/10.1111/j.1365-2788.2010.01258.x

4. Watermeyer B, McKenzie JA. Mothering of disabled children: In mourning or on March? Journal of Social Work Practice. 2014;28 (4):405-416. https://doi.org/10.1080/02650533.2014.889103

5. Lee AR. A structural model of caring behavior of mothers of disabled children. Journal of Korean Academy of Nursing. 2009;39 (5):73-682. https://doi.org/10.4040/jkan.2009.39.5.673

6. Miodrag N, Burke M, Tanner-Smith E, Hodapp RM. Adverse health in parents of children with disabilities and chronic health conditions: A meta-analysis using the parenting stress index's health sub-domain. Journal of Intellectual Disability Research. 2015;59(3): 257-271. https://doi.org/10.1111/jir.12135

7. Norlin D, Broberg M. Parents of children with and without intellectual disability: Couple relationship and individual well-being. Journal of Intellectual Disability Research. 2013;57(6):552-566. https://doi.org/10.1111/j.1365-2788.2012.01564.x 
8. Wieland N, Green S, Ellingsen R, Baker BL. Parent-child problem solving in families of children with or without intellectual disability. Journal of Intellectual Disability Research. 2014;58(1):17-30. https://doi.org/10.1111/jir.12009

9. Madi SM, Mandy A, Aranda K. The perception of disability among mothers living with a child with cerebral palsy in Saudi Arabia. Global Qualitative Nursing Research. 2019;6:1-11. https://doi.org/10.1177/2333393619844096

10. Sahu A, Bhargava R, Sagar R, Mehta M. Perception of families of children with specific learning disorder: An exploratory study. Indian Journal of Psychological Medicine. 2018;40(5):406-413. https://doi.org/10.4103/IJPSYM.IJPSYM_148_18

11. Ginieri-Coccossis M, Rotsika V, Skevington S, Papaevangelou S, Malliori M, Tomaras V, et al. Quality of life in newly diagnosed children with specific learning disabilities (SpLD) and differences from typically developing children: A study of child and parent reports. Child: Care, Health and Development. 2012;39(4):581-591. https://doi.org/10.1111/j.1365-2214.2012.01369.x

12. Gnanavel S. Maternal depression and anxiety in children and adolescents with intellectual disability. 2019;10(4):728-730. https://doi.org/10.1055/s-0039-3400349

13. Kim SS, Jung HJ. A study of effect that economic stress and depression have on child neglect in developmental disability children's mothers: The moderating effects of social support. Journal of Emotional and Behavioral Disorders. 2010;26(3):257-275.

14. Svensson B, Eriksson UB, Janson S. Exploring risk for abuse of children with chronic conditions or disabilities - Parent's perceptions of stressors and the role of professionals. Child: Care, Health and Development. 2013;39(6):887-893. https://doi.org/10.1111/cch.12030

15. Wei X, Yu JW. The concurrent and longitudinal effects of child disability types and health on family experiences. Maternal and Child Health Journal. 2012;16(1):100-108. https://doi.org/10.1007/s10995-010-0711-7

16. Lashewicz BM, Shipton L, Lien K. Meta-synthesis of fathers' experiences raising children on the autism spectrum. Journal of Intellectual Disabilities. 2019;23(1):117-131. https://doi.org/10.1177/1744629517719347

17. McConnell D, Savage A. Stress and resilience among families caring for children with intellectual disability: Expanding the research agenda. Current Developmental Disorders Reports. 2015;2: 100-109. https://doi.org/10.1007/s40474-015-0040-z

18. Lee AR, Hong SW, Kim JS, Ju SJ. Life transition of mothers of children with autism. Journal of Korean Academy of Nursing. 2010;40 (6):808-819. https://doi.org/10.4040/jkan.2010.40.6.808

19. Lee AR, Hong SW, Ju SJ. Development of a scale to measure life transition process in parents of children with autism. Journal of Korean Academy of Nursing. 2012;42(6):861-869. https://doi.org/10.4040/jkan.2012.42.6.861

20. Lee AR, Hong SW, Ju SJ. Construct validity of the life transition scale for parents of children with autism. Journal of Korean Academy of Nursing. 2014;44(5):563-572.

https://doi.org/10.4040/jkan.2014.44.5.563

21. Weiss JA, Cappadocia MC, MacMullin JA, Viecili M, Lunsky Y. The impact of child problem behaviors of children with ASD on parent mental health: The mediating role of acceptance and empowerment. Autism. 2012;16(3):261-274.

https://doi.org/10.1177/1362361311422708

22. Kim GS. New AMOS 18.0: Structural equation modeling analysis. Seoul: Hannarae Publishing Co.; 2010.

23. Lee AR, Hong SW. Differences in life transition process of parents caring for children with autism: Based on the socio-demographic characteristics. Child Health Nursing Research. 2015;21(4):331-338. https://doi.org/10.4094/chnr.2015.21.4.331

24. Shim SS, Nam JH. The effects of personal and social coping resources of mothers on the stress of caring adult children with developmental disabilities. Journal of Rehabilitation Research. 2016; 20(1):43-64. https://doi.org/10.16884/JRR.2016.20.1.43

25. Kim Y, Kim G, Kim S. A study on factors influencing the care burden of parents having children with developmental disabilities: The focus on the children's life cycle. The Women's Studies. 2015; 88(1):117-164.

26. Giallo R, Seymour M, Matthews J, Gavidia-Payne S, Hudson A, Cameron C. Risk factors associated with the mental health of fathers of children with an intellectual disability in Australia. Journal of Intellectual Disability Research. 2015;59(3):193-207. https://doi.org/10.1111/jir.12127

27. Dukmak S. Parent adaptation to and parenting satisfaction with children with intellectual disability in the United Arab Emirates. Journal of Intellectual and Developmental Disability. 2009;34(4): 324-328. https://doi.org/10.3109/13668250903286190

28. Piškur B, Beurskens AJHM, Jongmans MJ, Ketelaar M, Smeets RJEM. What do parents need to enhance participation of their school-aged child with a physical disability? A cross-sectional study in the Netherlands. Child: Care, Health and Development. 2015;41 (1):84-92. https://doi.org/10.1111/cch.12145

29. Minnes P, Perry A, Weiss JA. Predictors of distress and well-being in parents of young children with developmental delays and disabilities: The importance of parent perception. Journal of Intellectual Disability Research. 2015;59(6):551-560. https://doi.org/10.1111/jir.12160

30. Parish SL, Rose RA, Swaine JG. Financial well-being of US parents caring for coresident children and adults with developmental disabilities: An age cohort analysis. Journal of Intellectual and Developmental Disabilities. 2010;35(4):235-243.

https://doi.org/10.3109/13668250.2010.519331 